\title{
Sperm removal, ejaculation and their behavioural interaction in male cuttlefish in response to female mating history
}

\author{
Toshifumi Wada $^{1, *}$, Takeshi Takegaki ${ }^{1}$, Tohru Mori $^{2}$, Yutaka Natsukari $^{1}$ \\ ${ }^{1}$ Graduate School of Science and Technology, Nagasaki University, Japan \\ ${ }^{2}$ Marine World Uminonakamichi, Fukuoka, Japan
}

${ }^{*}$ Correspondence and present address: T. Wada, Coastal Branch of Tottori Prefectural Museum, 1794-4 Makidani, Iwami-cho, Tottori 681-0001, Japan

E-mail:wadat@pref.tottori.jp

${ }^{1}$ Graduate School of Science and Technology, Nagasaki University, 1-14 Bunkyo-machi, Nagasaki 852-8521, Japan

${ }^{2}$ Marine World Uminonakamichi, 18-28 Saitozaki, Higashi-ku, Fukuoka 811-0321, Japan

The removal of previously stored rival sperm and increased ejaculate expenditure are effective male sperm competition tactics to ensure paternity. We examined both behaviours and their interaction for male cuttlefish, Sepia lycidas, as a strategic investment. Males increased the duration of sperm removal and the number of ejaculations per mating when they were not the last male who had mated with the current partner. These responses would decrease the number of rival sperm and increase the male's own sperm in the fertilization area. Recognition of the female's mating history appeared to result from close mate guarding during successive matings. Moreover, when the last mate of the current partner was different from the current mate, there was a significant negative relationship between sperm removal duration and the number of subsequent ejaculations. This interaction suggests both strategic investment allocation and constraints on each mating investment as possible results of mating interruption by other males and spermatophore depletion, respectively. In addition, larger males with high competitive ability prolonged sperm removal when the last mate of the current partner was different from the current mate, whereas smaller males with relatively larger testes ejaculated more times during a mating. Male $\mathrm{S}$. lycidas might adjust the duration of sperm removal at the risk of failing to achieve ejaculation and allocate their finite ejaculate expenditures based on the results (i.e. the increasing proportion of their own sperm).

\section{Keywords}

cephalopod; ejaculatory behaviour; female mating history; kisslip cuttlefish; promiscuity; Sepia lycidas; sperm competition; sperm displacement; sperm removal behaviour 
Sperm competition occurs when the sperm from more than one male compete for fertilization of a female's eggs. This process is widely recognized as a major selective force in the evolution of mating systems and strategies ( [Parker, 1970] and [Parker, 1998]). The outcome of sperm competition is mediated largely by the relative numbers of sperm from competing males (Birkhead \& Møller 1998; but see Snook 2005). Two principal methods for increasing the relative number of a male's sperm are (1) an increase in ejaculate volume and (2) the removal of rival sperm. Recent studies have demonstrated that both strategic ejaculation and sperm removal are adaptive responses to enhance a male's fertilization success (e.g. [Simmons, 2001], [Córdoba-Aguilar et al., 2003] and [Williams et al., 2005]), but their interaction has not been addressed in previous experimental studies of sperm competition.

Sperm are smaller and cheaper to produce than eggs, but are not a limitless resource ( [Dewsbury, 1982] and [Nakatsuru and Kramer, 1982]). Many recent studies have shown that optimal allocation tactics for the limited number of available sperm have evolved to maximize male reproductive success ( [Pilastro et al., 2002], [Wedell et al., 2002], [Evans et al., 2003] and [Thomas and Simmons, 2007]). In some insects, males can perceive female mating status (i.e. virgin or mated female) by detecting the presence of sperm in the female sperm storage organ and can avoid mating with previously mated females to avoid a high level of sperm competition ( [Wedell and Cook, 1999] and [Schaus and Sakaluk, 2001]). The benefit to males from mating with previously mated females depends on the patterns of female sperm utilization, and particularly on the relationship between mating order and sperm precedence ( [Parker et al., 1997] and [Simmons, 2001]). In polyandrous (promiscuous) species with high female remating rates, first-male precedence will favour an increased investment in ejaculate during matings with virgin females, whereas such an increase is not necessarily predicted under last-male precedence (Parker et al. 1997: Engqvist \& Reinhold 2006). If the degree of last-male sperm precedence is sufficiently high, males mating with already mated females will have high fertilization success for a small ejaculate investment. However, if there is no sperm precedence, males should increase their ejaculate investment because fertilization success depends primarily on the number of sperm.

Male ejaculate investment would be expected to vary in relation to the mating tactics used by each male, because the probability of sperm competition differs between male reproductive types ( [Petersen and Warner, 1998] and [Wedell et al., 2002]). For example, larger males may compete for females and gain exclusive access to their partners, thereby allowing mating with a low risk of sperm competition. On the other hand, smaller males often adopt noncompetitive behavioural tactics such as sneaking and female mimicry and are always subject to sperm competition ( [Gross, 1996] and [Taborsky, 1998]). To compensate for such a disadvantageous situation, small, subordinate males should invest more heavily in traits related to ejaculate production (Parker 1990). This prediction has been supported in salmon, Salmo salar, and in dung beetles of the genus Onthophagus which have alternative male mating strategies: 'guard' and 'sneak' ( [Gage et al., 1995] and [Simmons et al., 1999]). In the bluegill 
sunfish, Lepomis macrochirus, small sneaker or satellite males have relatively larger testes and ejaculate greater numbers of sperm than large guarding males (Neff et al. 2003), and thereby gain higher fertilization success (Fu et al. 2001).

Another strategy for males to increase the relative number of their own sperm is the removal of previously stored rival sperm from the female's sperm storage organ ( [Simmons and Siva-Jothy, 1998] and [Simmons, 2001]). Many studies of insects have revealed that a copulating male removes previously deposited sperm either directly (e.g. removal by a specifically modified penis; Waage 1979) or indirectly (e.g. removal of the incoming ejaculate; Ono et al. 1989), thereby effectively avoiding competition with the sperm of rivals stored in the sperm storage organ. If a male can remove all stored sperm from the female's sperm storage organ, his ejaculate effort should be minimized (Parker 1998). The models of Parker and his collaborators predict that the ejaculate effort depends on the magnitude of the possibility of sperm competition even in the case of partial sperm removal ( [Parker et al., 1990] and [Parker and Simmons, 1991]). However, it is difficult to measure simultaneously both the degree of sperm removal and subsequent ejaculate expenditure because the mating events occur within the female's sperm storage organ in most insects.

Recently, possible removal of rival sperm has been reported for the common European cuttlefish, Sepia officinalis (Cephalopoda: Sepiidae; [Boal, 1997] and [Hanlon et al., 1999]), and the giant Australian cuttlefish, Sepia apama ( [Hall and Hanlon, 2002] and [Naud et al., 2004]). Some field and laboratory studies on large Sepia species, including the two above-mentioned species, indicate that the mating systems are complex, and that sperm competition is a central feature of their mating systems ([Hanlon and Messenger, 1996] and [Hanlon et al., 1999]). Both sexes mate promiscuously. The males deposit spermatophores on the ventral portion of the female's buccal membrane, where the paired seminal receptacle lies, but many sperm masses (spermatangia) ejected from the spermatophores are retained around the female's buccal area without being accommodated in the seminal receptacle. All ovulated eggs are most likely to be fertilized around the buccal area after having been transferred into the female's arms through her funnel (e.g. Naud et al. 2005). Before ejaculation, male $\mathrm{S}$. officinalis and $\mathrm{S}$. apama repeatedly flush strong jets of water through their funnels towards the female's buccal areas ( [Hanlon et al., 1999] and [Hall and Hanlon, 2002]). This flushing behaviour has been reported to result in the removal of spermatangia from previous matings, but no significant relationship between the flushing duration and fertilization success has been detected (Naud et al. 2004). In our previous study of $S$. esculenta, we found that active sperm were present within the removed sperm debris, and that the sperm removal behaviour made it possible to assess the elapsed time visually and use this parameter as an indicator of the male investment allocated to sperm removal (Wada et al. 2005). After the sperm removal or flushing behaviour, the males ejaculate once during each mating ( [Hanlon et al., 1999], [Wada et al., 2005] and [Wada et al., 2006]). Although it has been reported that male S. apama often performed double ejaculations in a single mating (19\% of 31 successful matings; Hall \& Hanlon 2002), the body sizes of the mated pair and the situation in 
which the matings occurred were not recorded.

In the present study, we investigated the factors affecting sperm removal and ejaculate expenditure for male kisslip cuttlefish, Sepia lycidas, in captivity. We also endeavoured to reveal the relationship between the two major aspects of sperm displacement strategy (i.e. sperm removal and ejaculate expenditure) using visible characteristics that provided an indirect measure of both forms of reproductive investment by males during each mating.

\section{Methods}

\section{Animals and Maintenance Conditions}

Sepia lycidas is distributed throughout the eastern and southern China Sea, including in areas near southern Japan (Okutani 2005). The species grows rapidly and achieves its maximum mantle length (ca. $38 \mathrm{~cm}$ ) during a short life span of about 1 year (Natsukari \& Tashiro 1991). Mature males and females migrate into shallow coastal areas such as Zostera beds to mate and spawn early in the breeding season (April to July in southern Japan; Natsukari \& Tashiro 1991; T. Wada, personal observation).

In the present study, sexually mature $\mathrm{S}$. Iycidas $(\mathrm{N}=50)$ were captured using small set nets off the coast of Tsuyazaki (33 $\left.47^{\prime} \mathrm{N}, 130^{\circ} 26^{\prime} \mathrm{E}\right)$ in Fukuoka Prefecture, Kyushu, Japan, between April and June 2002. The animals were transported by truck in a fibre-reinforced plastic container to the Marine World Uminonakamichi aquarium where they were placed in an observation tank $(3.2 \times 6.6 \mathrm{~m}$ and $1.8 \mathrm{~m}$ deep, about 38000 litres) with an acrylic window $(1.5 \times 5.2 \mathrm{~m})$. We kept an average \pm SD of $15.2 \pm$ 7.1 individuals/day in the tank during the study period from 21 April to 20 June. The sex ratio was male biased throughout the study period as a result of the ratio in our samples (61.5-93.7\% males).

The observation tank was supplied constantly with natural seawater (1680 litres/h), and some branches were provided as a spawning substrate on the sandy bottom. Water temperature was maintained at $19.0 \pm 0.5^{\circ} \mathrm{C}$. Water quality (i.e. $\mathrm{pH}$ and ammonia, nitrite and nitrate levels) was measured once every 2 weeks, and the parameter values (mean \pm SD: $\mathrm{pH}: 7.57 \pm 0.16 ; \mathrm{NH} 4-\mathrm{N}: 0.01 \pm 0.01$ ppm; NO3-N: $1.6 \pm 0.7 \mathrm{ppm}$; NO2-N: $0.015 \pm 0.021 \mathrm{ppm}$ ) were within the ranges reported for multiple-culture systems of other cuttlefish (Forsythe et al. 1994) and squid (Walsh et al. 2002). Artificial light (3200 Ix at the surface of the tank) was typically provided from 0600 to 1930 hours, but the lighting period was sometimes extended until 2100 hours for observation and recording. The animals in the tank were fed either previously frozen fish or shrimp daily (1700-1800 hours) and sometimes fresh fish that were obtained dead from fishermen using set nets. After the study, the cuttlefish remained in the tank until they died a natural death after reproduction. To avoid handling stress, we measured the body size of the cuttlefish only after their death. Males had a mean mantle length \pm SD of $23.7 \pm$ $3.5 \mathrm{~cm}$ (range $17.8-31.0 \mathrm{~cm}, \mathrm{~N}=32$ ); females had a mean length of $21.5 \pm 2.9 \mathrm{~cm}$ (range $16.2-25.5 \mathrm{~cm}, \mathrm{~N}=18$ ).

\section{Data Sampling and Individual Identification}


Behavioural observations and recordings were obtained through the window of the tank, primarily in the morning (0600-0830 hours) and evening (1700-1930 hours), because sexual behaviour of $\mathrm{S}$. lycidas was seen during these hours in nature (T. Wada, personal observation). In this study, we made videotape recordings for $14.1 \mathrm{~h}$ by close-up ad libitum sampling and for $119.5 \mathrm{~h}$ by continuous focal animal sampling (Martin \& Bateson 1993) with two digital video cameras, models DCR-VX1000 and CCD-TR1000-NTSC (Sony, Tokyo, Japan), respectively. The former was hand-held to record each phase of the mating sequence in detail, and the latter was mounted on a tripod to record continuous series of pairing and egg-laying behaviours using a wide-angle setting.

We used lip marks on the dorsal mantle or unique scars on one or more body parts as specific external characteristics for the identification of individuals. Individual characteristics were recorded with the digital video cameras almost every day. The cuttlefish were sexed by the body patterns of the dorsal mantle and by their behaviour.

For analysis, we used two successive matings of 27 different males in the tank, which had been videorecorded without interruption (i.e. no other mating between those successive matings). Of these focal 27 males, 18 males mated with two different females in their successive matings and the other nine males mated with the same female repeatedly. We compared mating behaviour in the second mating of the two successive matings between these two groups of males to investigate the effects of the last-mated partner (i.e. same female or not) on male mating behaviour. In analysing of the effect of female body size on male sperm removal duration and the number of ejaculations, we used only the first mating of 15 females observed in the tank. All females used in this study had already mated before they were caught because we observed sperm masses at the ventral portion of each female's buccal area.

\section{Estimations of Sperm Removal and Ejaculate Expenditure}

We used the time allocated to sperm removal behaviour as an indicator of a male's investment in sperm removal, as has been used for the congeneric S. esculenta, because of the positive correlation between the number of removed sperm masses and the removal duration (Wada et al. 2005). As was the case for S. esculenta, S. lycidas males scraped off sperm masses previously attached to a female's buccal area using their arms, resulting in the scattering of much sperm debris in the water column (see the Supplementary material for details: video S1). Although the sperm removal duration may depend on the quantity of sperm masses deposited in the female's buccal area, it was not related to the number of ejaculations at the female's last mating or at the last two matings (Spearman correlation: $r_{S}=-0.09, N=22, P>0.05 ; r S=-0.22, N=8, P>$ 0.05 , respectively). After the sperm removal behaviour, we used the number of ejaculations during a single mating as an indicator of the ejaculate expenditure by males. The ejaculatory behaviour can be clearly determined by movements of the male's hectocotylized left fourth arm (see Supplementary material: video S2). The ejaculate expenditure may be influenced by the mating intervals ( [Birkhead, 1991] and [Parker, 1998]), but no significant correlation between the number of ejaculations and the mating 
interval was detected in the present study $\left(r_{S}=-0.22, N=11, P>0.05\right)$. All video analyses for estimating the expenditures for the sperm removal and ejaculation were carried out on a high-resolution monitor (PVM-14M4J, Sony). Both estimations of the male reproductive expenditures are less accurate than direct sperm counts, but there are no alternatives for assessing the interaction between sperm removal and ejaculate expenditure without disrupting the cuttlefish. Although a few mating events were interrupted by the interference of other males, we regarded those mating events as a single mating because the males restarted their mating immediately.

\section{Sperm Removal and Ejaculate Expenditure Analysis}

Sperm removal and ejaculate expenditure could be affected by the perceived degree of sperm competition (e.g. [Birkhead and Møller, 1998] and [Simmons, 2001]). In some Sepia species, many spermatangia ejected from the spermatophores that males deposit on the ventral portion of the female's buccal membrane (i.e. the fertilization area) are retained around the female's buccal area without being accommodated in the seminal receptacle. In S. apama, sperm that successfully fertilize ova are more likely to have come from spermatangia on the female's buccal membrane (attached by recent matings) rather than sperm present in the seminal receptacle (Naud et al. 2005). Although it is not unclear whether sperm precedence favours sperm attached around the female's buccal membrane (Naud et al. 2005), males of both S. apama and S. lycidas remove the sperm attached around the female's buccal area just before ejaculation, strongly suggesting that sperm attached by the previous matings remain in this location and could be a rival's sperm. Thus, in this study, we used female mating history (i.e. whether the last male who mated with a female was the current male or a different male) as an indicator of the degree of sperm competition, and examined the effect of this parameter on the sperm removal behaviour and ejaculate expenditure for each mating.

Moreover, we examined the effects of the body sizes of both males and females on the sperm removal duration and the number of ejaculations per mating and used the size of the individuals as indicators of male social status and female fecundity, respectively. A positive relationship between male competitive ability and the male's relative body size has been reported for other cuttlefish species ( [Adamo and Hanlon, 1996] and [Boal, 1996]). Similarly, larger male S. Iycidas, in particular, compete more successfully for females and form pairs ( $T$. Wada, unpublished data). Female fecundity is related to their body size and age (Wedell et al. 2002).

\section{Statistical Analysis}

We used nonparametric tests because the data for sperm removal duration and the number of ejaculations were not normally distributed (Kolmogorov-Smirnov one-sample test: $P<0.05)$, even after attempting several transformations. We assessed the effects of female mating history on the male's sperm removal behaviour and ejaculate expenditure using the Mann-Whitney $U$ test. We assessed the relationships between the sperm removal duration, the number of ejaculations during a mating, and the body 
sizes of the males and females by means of Spearman correlation analyses. All statistical analyses were performed using version 16.0 of SPSS (SPSS Inc., Chicago, IL, U.S.A.).

\section{Results}

\section{Mating Behaviour of Sepia lycidas}

Male S. lycidas competed for access to females, particularly during and immediately before the female egg-laying period. The paired male usually stayed beside or on his partner, and mated with her mainly during her egg-laying period. The mating occurred in a head-to-head position so that the arms of the pair were intertwined. First, the male scraped off sperm masses previously attached to the ventral portion of the female's buccal area with his third arms and right fourth arm (duration: mean $\pm \mathrm{SD}=90.5 \pm 70.3$ $\mathrm{s}$, range 5-249 s, $\mathrm{N}=27$ ), resulting in the dispersal of sperm debris into the water column. After this sperm removal behaviour, the male ejaculated spermatophores through his funnel and then transferred them to the female buccal area with his hectocotylized left fourth arm. This ejaculatory behaviour, with spermatophore transfer, was performed an average \pm SD of $2.9 \pm 1.2$ times in a single mating (range 1-5 times, $\mathrm{N}=27$ ). The time spent on the ejaculation, including the attachment of spermatophores, increased with increasing ejaculate number (mean time \pm SD: with one ejaculation: 12.7 $\pm 4.0 \mathrm{~s}, \mathrm{~N}=3$; with two: $27.3 \pm 6.7 \mathrm{~s}, \mathrm{~N}=8$; with three: $34.4 \pm 6.1 \mathrm{~s}, \mathrm{~N}=9$; with four: 67.5 $\pm 9.8 \mathrm{~s}, \mathrm{~N}=4$; with five: $71.0 \pm 4.5 \mathrm{~s}, \mathrm{~N}=3$ ). Both males and females mated with multiple partners during the breeding period, as was expected because of the promiscuous mating system of this species.

\section{Sperm Removal Tactics and Ejaculate Allocation}

The male cuttlefish spent significantly more time on sperm removal behaviour when the last male who had mated with the current partner was a different male (mean $\pm \mathrm{SD}=$ $122.2 \pm 62.1 \mathrm{~s}$, range $39-249 \mathrm{~s}, \mathrm{~N}=18)$ rather than the current male $(27.1 \pm 33.2 \mathrm{~s}$, 5-102 s, N = 9; Mann-Whitney U test: $Z=-3.62$, $P<0.001$; Fig. 1). The sperm removal duration was not significantly affected by the body size of the male $(r S=0.006, N=27$, $P>0.05)$ or of the female $(r S=0.12, N=15, P>0.05)$.

The male ejaculated significantly more frequently when the last male who had mated with the current partner was a different male $(3.4 \pm 1.0$ times, range $2-5$ times, $N=18)$ rather than the current male $(1.8 \pm 0.7$ times, range $1-3$ times, $N=9 ; Z=-3.54, P<$ 0.001 ; Fig. 2). The number of ejaculations during a mating was negatively correlated with male body size $(r S=-0.41, N=27, P<0.05)$, but not with female body size ( $r S=-$ $0.45, \mathrm{~N}=15, \mathrm{P}>0.05)$.

When the last male who had mated with the current partner was not the current male but a different male $(\mathrm{N}=18)$, a significant negative relationship between the sperm removal duration and the number of subsequent ejaculations was detected ( $r S=-0.487$, $P<0.05$; Fig. 3). Moreover, in such situations, multiple-correlation analyses showed that larger males prolong the sperm removal duration compared with smaller males ( $\mathrm{SS}$ $=0.54, \mathrm{P}<0.05$; Fig. $4 \mathrm{a}$ ), and that smaller males ejaculate more frequently than larger 
males during a mating ( $r S=-0.54, P<0.05$; Fig. $4 b)$.

\section{Discussion}

\section{Response to Female Mating History}

Male S. lycidas increased their number of ejaculations during a mating when the last male who had mated with their partner was a different male. Because the sperm are attached to and retained on the female's buccal area in this species (Wada 2005), the males would have increased their ejaculate expenditure to increase the proportion of their own sperm at the fertilization site. This is the first evidence of strategic ejaculate allocation among cephalopods, although similar results predicted by sperm competition theory (Parker et al. 1997) have been reported in several taxa (e.g. [Marconato and Shapiro, 1996], [Pizzari et al., 2003] and [Pound and Gage, 2004]). In addition to using strategic ejaculation, male $S$. lycidas adjusted their sperm removal duration in response to the female's mating history, with long and short removal durations when the last male who had mated with the current partner was a different male and the current male, respectively. When the last male was different, the rival's sperm should usually remain on the female's buccal area without being used for fertilization. Because the quantity of sperm that is removed increases with the time spent in removal behaviour (Wada et al. 2005), the long removal duration could be an adaptive tactic for males to improve their reproductive success with females who had previously mated with a different male. On the other hand, adopting a short removal duration when the male's own sperm masses remained in the female's buccal area after the previous mating can be attributed to an adaptation to avoid removing one's own sperm. Although it is also possible that the sperm removal duration depends on the quantity of sperm attached to the female's buccal area, the noticeable difference in removal duration as a function of the female's previous mating partner indicates that males determine the removal duration principally based on their perception of the female's mating history. Thus, these results strongly suggest that males recognize a female's mating history in some way, and thereby adjust their sperm removal duration and ejaculate expenditure accordingly. In other animals, it has been suggested that males assess the level of sperm competition via sperm storage cues or other evidence of recent mating such as female age (e.g. [Cigliano, 1995], [Yasui, 1996] and [Sauter and Brown, 2001]). How do male S. lycidas recognize a female's mating history?

In other species in which males remove sperm, the males discriminate between virgin and mated females by detecting the presence of sperm in the female's sperm storage organ ( [Cordero and Miller, 1992] and [Uhía and Cordero Rivera, 2005]). However, in promiscuous species with frequent matings, including S. lycidas, the ability of males to detect sperm would seem to have little advantage because of the smaller opportunity to meet virgin females. In S. Iycidas, male mate-guarding behaviour may make it possible to recognize the mating history of the female. This is because pairs usually mate repeatedly and engage multiple times in subsequent egg laying, during which time the paired male stays close to his partner to guard against other males (Wada 2005). Indeed, in two cases in the present study in which mate guarding after 
mating had not been completed because of male-male competition, the subsequent sperm removal durations were considerably longer than in the other cases during successive matings by the same male (102 s and $46 \mathrm{~s}$, respectively). Males probably recognize the female's mating history as a result of their continuous guarding of their mate and follow a simple rule: they perform removal behaviour for longer and ejaculate more frequently when the mating history of their current partner is uncertain.

The ability of male $\mathrm{S}$. lycidas to adjust their sperm removal behaviour based on the female's perceived mating history would help males to reduce their rival's sperm effectively and enhance their own paternity (e.g. [Hanlon et al., 1999] and [Wada et al., 2005]), as predicted by sperm displacement models ( [Parker et al., 1990], [Parker and Simmons, 1991] and [Parker, 1998]). However, if males have high fertilization success as a result of the removal of a rival's sperm, it remains unclear why they both increased their sperm removal expenditure and increased their ejaculate expenditure based on the female's perceived mating history. In a sperm-removing freshwater crayfish, Austropotamobius italicus, males who mated with previously mated females did not increase their ejaculate size because they can remove a high proportion of a rival's stored sperm from the female sperm storage organ ( [Galeotti et al., 2007] and [Galeotti et al., 2008]). Thus, the degree of sperm removal in S. lycidas may influence the male's subsequent ejaculate expenditure.

\section{Sperm Removal and Ejaculate Expenditure Interaction}

When the last male who had mated with the current partner was a different male, the relationship between sperm removal duration and the number of subsequent ejaculations by male S. lycidas was significantly negative: large and small numbers of ejaculations occurred subsequent to short and long durations of sperm removal, respectively. The negative relationship between sperm removal and ejaculate expenditure suggests the presence of not only a strategic interaction but also of quantitative constraints on each behaviour.

The most influential constraint on sperm removal behaviour is likely to be mating interruption by other males, because these interruptions often resulted in the end of mating behaviour without ejaculation. This hypothesis is likely to be supported by the longer sperm removal duration by larger males, which have an advantage over smaller males during male-male competition (Fig. 4a). To ensure ejaculation, the males must avoid having their mating behaviour interrupted before ejaculation, and, at the same time, they must also remove the previously attached sperm masses for as long as possible to enhance their own likelihood of paternity. The relative efficiency of these two conflicting behaviours in increasing a male's paternity is unclear, but ejaculation leading to mating success should be prioritized over sperm removal. Therefore, under a high degree of sperm competition and a high risk of mating interruption, males would compensate for a short duration of sperm removal by increasing the number of subsequent ejaculations.

Because the ejaculatory behaviour ends sooner than the sperm removal behaviour, it may be less constrained by time than by sperm depletion because of the high mating 
frequency (i.e. because of sperm limitation), as has been reported in several animal groups ( [Wedell et al., 2002] and [Kraus et al., 2004]). In a few fish that perform consecutive group spawning, males economize sperm by adjusting their ejaculate volume in response to the number of females or female body size ( [Shapiro et al., 1994] and [Marconato and Shapiro, 1996]). If such sperm depletion also occurs in S. lycidas, males should remove sperm for as long as possible to minimize the ejaculate expenditure required for successful fertilization. Male $\mathrm{S}$. Iycidas usually store more than 1000 spermatophores within their spermatophore sac (T. Wada, unpublished data), but this amount might not be sufficient under the conditions of repeated matings and intense sperm competition because of the large number of spermatophores used in a single mating. In the present study, we observed at least several dozen outer sheaths of the spermatophores ejected from the female's buccal area immediately after mating. Moreover, in S. officinalis, more than 200 spermatophores have been used during a single mating (Hanlon et al. 1999). In S. lycidas, the sperm limitation hypothesis may be supported by the higher frequency of ejaculations by smaller males (Fig. 4b), which have larger testes than those of larger males (Wada 2005).

The present study suggested that male $S$. lycidas adjust their sperm removal duration and their number of subsequent ejaculations complementarily when the last male who mated with their partner was a different male, probably to increase the relative proportion of their own sperm in the female's buccal area. The negative relationship between sperm removal duration and the number of ejaculations suggests that sperm removal in this species is not complete (i.e. is partial), and both theoretical and empirical studies have suggested that there is no reason to adjust ejaculate investment if the males can completely or nearly completely remove a rival's stored sperm ( [Parker, 1998] and [Galeotti et al., 2007]). Thus, male S. lycidas would perceive the degree of their sperm removal and control the subsequent ejaculate expenditure. The compensatory investment allocation for the two behaviours is inevitably affected by the sperm removal duration because removal is conducted before ejaculation. In addition, whether males are able to ejaculate also depends on the removal behaviour because ejaculation was frequently interrupted by interference from other males, and the interrupted matings often ended without ejaculation. The presence of sperm removal behaviour involving a high risk of failure to reach ejaculation suggests a striking effect of sperm removal on the increase in paternity. To test this hypothesis, genetic analysis to determine the relative effect of sperm removal and strategic ejaculation will be needed.

\section{Acknowledgments}

We thank the staff of Marine World Uminonakamichi, who enabled us to perform this study and assisted us greatly in the capture and maintenance of live cuttlefish. We are also grateful to Geoff A. Parker, Marie-J. Naud and Jonathan P. Evans for their helpful suggestions on the manuscript. Tommaso Pizzari and the anonymous referees provided critical comments and suggestions that greatly improved the paper.

\section{Supplementary Material}


http://www.sciencedirect.com/science/article/pii/S0003347209005624

\section{References}

Adamo, S. A. \& Hanlon, R. T. 1996. Do cuttlefish signal their intention to conspecifics during agonistic encounters? Animal Behaviour, 52, 73-81.

Birkhead, T. R. 1991. Sperm depletion in the Bengalese finch, Lonchura striata. Behavioral Ecology, 2, 267-275.

Birkhead, T. R. \& Møller, A. P. 1998 Sperm competition and sexual selection. Academic Press, London.

Boal, J. G. 1996. Absence of social recognition in laboratory-reared cuttlefish, Sepia officinalis L. (Mollusca: Cephalopoda). Animal Behaviour, 52, 529-537.

Boal, J. G. 1997. Female choice of males in cuttlefish (Mollusca: Cephalopoda). Behaviour, 134, 975-988.

Cigliano, J. A. 1995. Assessment of the mating history of female pygmy octopuses and a possible sperm competition mechanism. Animal Behaviour, 49, 849-851.

Cordero, A. \& Miller, P. L. 1992. Sperm transfer, displacement and precedence in Ischnura graellsii (Odonata: Coenagrionidae). Behavioral Ecology and Sociobiology, 30, 261-267.

Córdoba-Aguilar, A., Uhía, E. \& Cordero-Rivera, A. 2003. Sperm competition in Odonata (Insecta): the evolution of female sperm storage and rivals' sperm displacement. Journal of Zoology (London), 261, 381-398. doi: $10.1017 /$ S0952836903004357

Dewsbury, D. A. 1982. Ejaculate cost and male choice. American Naturalist, 119, 601-610.

Engqvist, L. \& Reinhold, K. 2006. Theoretical influence of female mating status and remating propensity on male sperm allocation patterns. Journal of Evolutionary Biology, 19, 1448-1458. doi: 10.1111/j.1420-9101.2006.01134.x

Evans, J. P., Pierotti, M. \& Pilastro, A. 2003. Male mating behavior and ejaculate expenditure under sperm competition risk in the eastern mosquitofish. Behavioral Ecology, 14, 268-273.

Forsythe, J. W., DeRusha, R. H. \& Hanlon, R. T. 1994. Growth, reproduction and life span of Sepia officinalis (Cephalopoda: Mollusca) cultured through seven consecutive generations. Journal of Zoology (London), 233, 175-192.

Fu, P., Neff, B. D. \& Gross, M. R. 2001. Tactic-specific success in sperm competition. Proceedings of the Royal Society of London, Series B, 268, 1105-1112. doi: 10.1098/rspb.2001.1625.

Gage, M. J. G., Stockley, P. \& Parker, G. A. 1995. Effects of alternative male mating strategies on characteristics of sperm production in the Atlantic salmon (Salmo salar): theoretical and empirical investigations. Philosophical Transactions of the Royal Society of London, Series B, 350, 391-399. 
Galeotti, P., Pupin, F., Rubolini, D., Sacchi, R., Nardi, P. A. \& Fasola, M. 2007. Effects of female mating status on copulation behaviour and sperm expenditure in the freshwater crayfish Austropotamobius italicus. Behavioral Ecology and Sociobiology, 61, 711-718. doi: 10.1007/s00265-006-0301-2

Galeotti, P., Rubolini, D., Pupin, F., Sacchi, R. \& Fasola, M. 2008. Sperm removal and ejaculate size correlate with chelae asymmetry in a freshwater crayfish species. Behavioral Ecology and Sociobiology, 62, 1739-1745. doi: 10.1007/s00265-008-0602-8

Gross, M. R. 1996. Alternative reproductive strategies and tactics: diversity within sexes. Trends in Ecology and Evolution, 11, 92-98.

Hall, K. C. \& Hanlon, R. T. 2002. Principal features of the mating system of a large spawning aggregation of the giant Australian cuttlefish Sepia apama. Marine Biology, 140, 533-545. doi: 10.1007/s00227-001-0718-0.

Hanlon, R. T. \& Messenger, J. B. 1996. Cephalopod behaviour. Cambridge University Press, Cambridge, United Kingdom.

Hanlon, R. T., Ament, S. A. \& Gabr, H. 1999. Behavioral aspects of sperm competition in cuttlefish, Sepia officinalis (Sepioidea: Cephalopoda). Marine Biology, 134, 719-728.

Kraus, F. B, Neumann, P., van Praagh, J. \& Moritz, R. F. A. 2004. Sperm limitation and the evolution of extreme polyandry in honeybees (Apis mellifera L.). Behavioral Ecology and Sociobiology, 55, 494-501. doi: 10.1007/s00265-003-0706-0.

Marconato, A. \& Shapiro, D. Y. 1996. Sperm allocation, sperm production and fertilization rates in the bucktooth parrotfish. Animal Behaviour, 52, 971-980.

Martin, P. \& Bateson, P. 1993. Measuring behaviour. An introductory guide, edn 2. Cambridge University Press, London.

Nakatsuru, K. \& Kramer, D. L. 1982. Is sperm cheap? Limited male fertility and female choice in the lemon tetra (Pisces, Characidae). Science, 216, 753-755.

Natsukari, Y. \& Tashiro, M. 1991. Neritic squid resources and cuttlefish resources in Japan. Marine Behavior \& Physiology, 18, 149-226.

Naud, M.-J., Hanlon, R. T., Hall, K. C., Shaw, P. W. \& Havenhand, J. N. 2004. Behavioural and genetic assessment of reproductive success in a spawning aggregation of the Australian giant cuttlefish, Sepia apama. Animal Behaviour, 67, 1043-1050. doi: 10.1016/j.anbehav.2003.10.005.

Naud, M.-J., Shaw, P. W., Hanlon, R. T. \& Havenhand, J. N. 2005. Evidence for biased use of sperm sources in wild female giant cuttlefish (Sepia apama). Proceedings of the Royal Society of London, Series B, 272, 1047-1051. doi: 10.1098/rspb.2004.3031.

Neff, B. D., Fu, P. \& Gross, M. R. 2003. Sperm investment and alternative mating tactics in bluegill sunfish (Lepomis macrochirus). Behavioral Ecology, 14, 634-641. doi: 10.1093/beheco/arg032. 
Okutani, T. 2005 Cuttlefishes and squids of the world. National Cooperative Association of Squid Processors, Tokyo.

Ono, T., Siva-Jothy, M. T. \& Kato, A. 1989. Removal and subsequent ingestion of rival's semen during copulation in a tree cricket. Physiological Entomology, 14, 195-202.

Parker, G. A. 1970. Sperm competition and its evolutionary consequences in the insects. Biological Reviews, 45, 525-567.

Parker, G. A. 1990. Sperm competition games: sneaks and extra-pair copulations. Proceedings of the Royal Society of London, Series B, 242, 127-133.

Parker, G. A. 1998. Sperm competition and the evolution of ejaculates: towards a theory base. In Sperm competition and sexual selection (Ed. T. R. Birkhead \& A. P. Møller), pp. 3-54, Academic Press, London.

Parker, G. A. \& Simmons, L. W. 1991. A model of constant random sperm displacement during mating: evidence from Scatophaga. Proceedings of the Royal Society of London, Series B, 246, 107-115.

Parker, G. A., Simmons, L. W. \& Kirk, H. 1990. Analysing sperm competition data: simple models for predicting mechanisms. Behavioral Ecology and Sociobiology, 27, 55-65.

Parker, G. A., Ball, M. A., Stockley, P. \& Gage, M. J. G. 1997. Sperm competition games: a prospective analysis of risk assessment. Proceedings of the Royal Society of London, Series B, 264, 1793-1802.

Petersen, C. W. \& Warner, R. R. 1998. Sperm competition in fishes. In Sperm competition and sexual selection (Ed. T. R. Birkhead \& A. P. Møller), pp. 435-463, Academic Press, London.

Pilastro, A. Scaggiante, M. \& Rasotto, M. B. 2002 Individual adjustment of sperm expenditure accords with sperm competition theory. Proceedings of the National Academy of Sciences USA, 99, 9913-9915. doi: 10.1073/pnas.152133499.

Pizzari, T., Cornwallis, C. K., Løvlie, H. Jakobsson, S. \& Birkhead, T. R. 2003. Sophisticated sperm allocation in male fowl. Nature, 426, 70-74. doi: 10.1038/nature02004.

Pound, N \& Gage, M. J. G. 2004. Prudent sperm allocation in Norway rats, Rattus norvegicus: a mammalian model of adaptive ejaculate adjustment. Animal Behaviour, 68, 619-623. doi: 10.1016/j.anbehav.2004.02.004.

Sauter, A. \& Brown, M. J. F. 2001. To copulate or not? The importance of female status and behavioural variation in predicting copulation in a bumblebee. Animal Behaviour, 62, 221-226. doi: 10.1006/anbe.2001.1742.

Schaus, J. M. \& Sakaluk, S. K. 2001. Ejaculate expenditures of male crickets in response to varying risk and intensity of sperm competition: not all species play games. Behavioral Ecology, 12, 740-745. doi: 10.1093/beheco/12.6.740.

Shapiro, D. Y., Marconato, A. \& Yoshikawa, T. 1994. Sperm economy in a coral reef fish Thalassoma bifasciatum. Ecology, 75, 1334-1344. 
Simmons, L. W. 2001. Sperm competition and its evolutionary consequences in the insects. Princeton University Press, Princeton, New Jersey.

Simmons, L. W. \& Siva-Jothy, M. T. 1998. Sperm competition in insects: mechanisms and the potential for selection. In Sperm competition and sexual selection (Ed. T. R. Birkhead \& A. P. Møller), pp. 341-434, Academic Press, London.

Simmons, L. W., Tomkins, J. L. \& Hunt, J. 1999. Sperm competition games played by dimorphic male beetles. Proceedings of the Royal Society of London, Series B, 266, 145-150.

Snook, R. R. 2005. Sperm in competition: not playing by the numbers. Trends in Ecology and Evolution, 20, 46-53. doi: 10.1016/j.tree.2004.10.011.

Taborsky, M. 1998. Sperm competition in fish: 'bourgeois' males and parasitic spawning. Trends in Ecology and Evolution, 13, 222-227.

Thomas, M. L. \& Simmons, L. W. 2007. Male crickets adjust the viability of their sperm in response to female mating status. American Naturalist, 170, 190-195.

Uhía, E. \& Cordero Rivera, A. 2005. Male damselflies detect female mating status: importance for postcopulatory sexual selection. Animal Behaviour, 69, 797-804. doi: 10.1016/j.anbehav.2004.08.005.

Waage, J. K. 1979. Dual function of the damselfly penis: sperm removal and transfer. Science, 203, 916-918.

Wada, T. 2005. Reproductive behavioral ecology in each three species of the loliginid squids and cuttlefishes (Mollusca: Cephalopoda). Doctoral dissertation, Nagasaki Univ. (in Japanese with English summary).

Wada, T., Takegaki, T., Mori, T. \& Natsukari, Y. 2005. Sperm displacement behavior of the cuttlefish Sepia esculenta (Cephalopoda: Sepiidae). Journal of Ethology, 23, 85-92. doi: 10.1007/s10164-005-0146-6.

Wada, T., Takegaki, T., Mori, T. \& Natsukari, Y. 2006. Reproductive behavior of the Japanese spineless cuttlefish Sepiella japonica. Venus, 65, 221-228.

Walsh, L. S., Turk, P. E., Forsythe, J. W. \& Lee, P. G. 2002. Mariculture of the loliginid squid Sepioteuthis lessoniana through seven successive generations. Aquaculture, 212, 245-262.

Wedell, N \& Cook, P. A. 1999. Butterflies tailor their ejaculate in response to sperm competition risk and intensity. Proceedings of the Royal Society of London, Series $B, 266,1033-1039$.

Wedell, N., Gage, M. J. G. \& Parker, G. A. 2002. Sperm competition, male prudence and sperm-limited females. Trends in Ecology and Evolution, 17, 313-320. doi: 10.1016/S0169-5347(02)02533-8.

Williams, P. D., Day, T. \& Cameron, E. 2005. The evolution of sperm-allocation strategies and the degree of sperm competition. Evolution, 59, 492-499.

Yasui, Y. 1996. Males of a mite, Macrocheles muscadomesticae, estimate a female's value on the basis of her age and reproductive status. Journal of Insect Behavior, 
9, 517-524. 


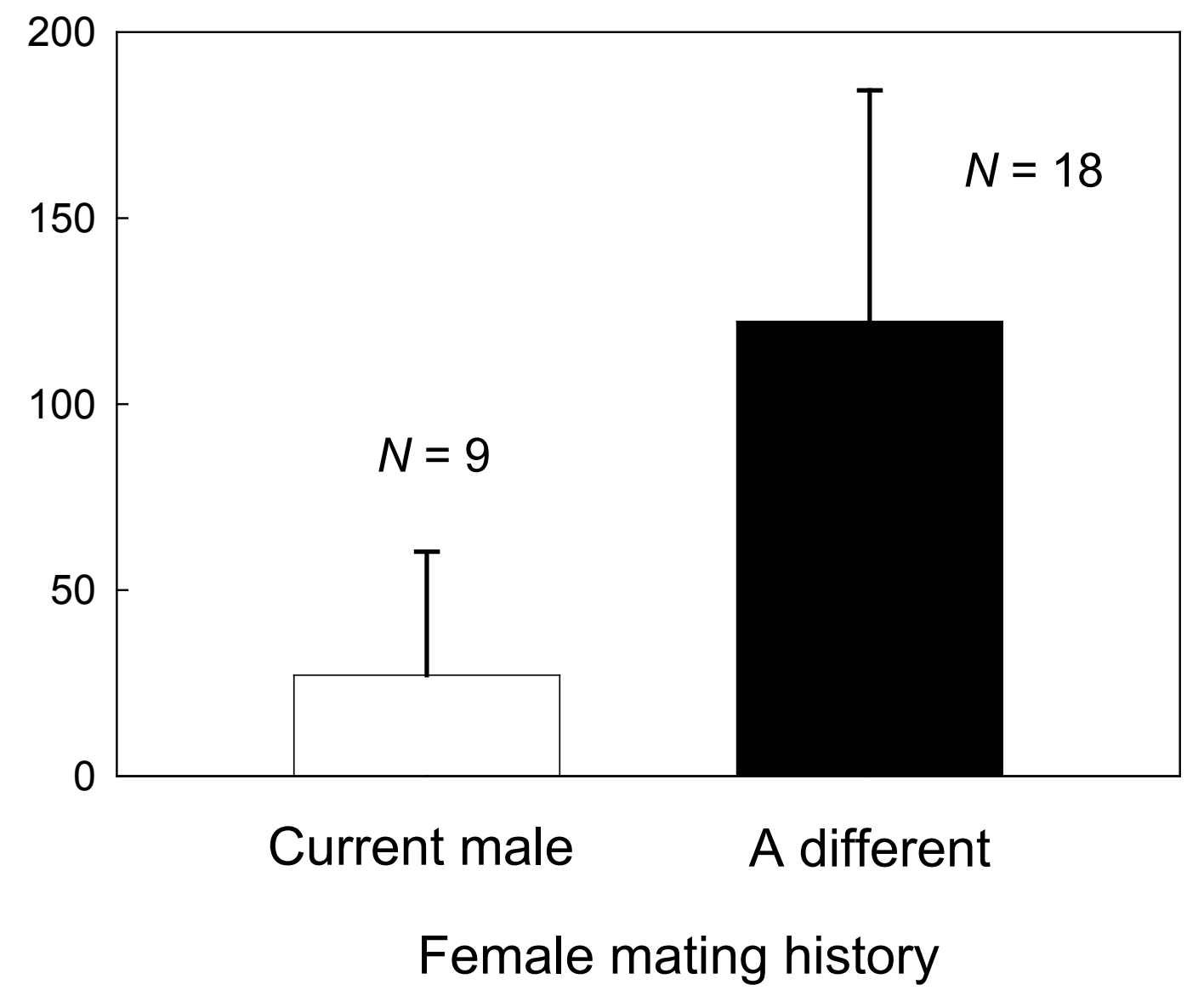

Figure 1. Sperm-removal durations by male Sepia lycidas (mean $\pm \mathrm{SD}$ ) differed significantly between situations in which the last male who had mated with the current partner was the current male or a different male. The sample sizes were 9 and 18 males, respectively. 


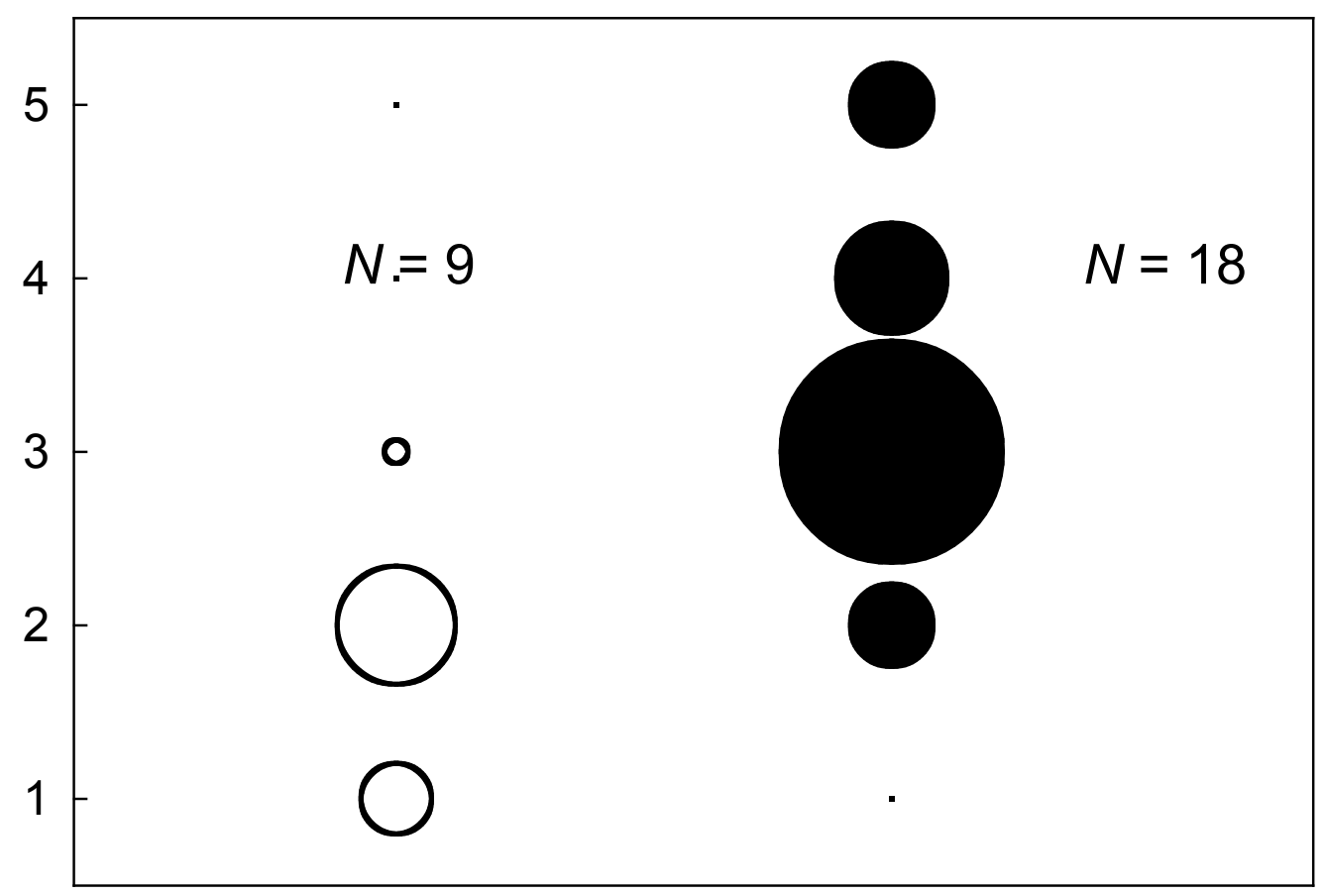

\section{Current male A different}

Female mating history

Figure 2. Number of ejaculations per mating as a function of female mating history. The size of the symbols represents the sample size: large dots represent larger sample sizes. 


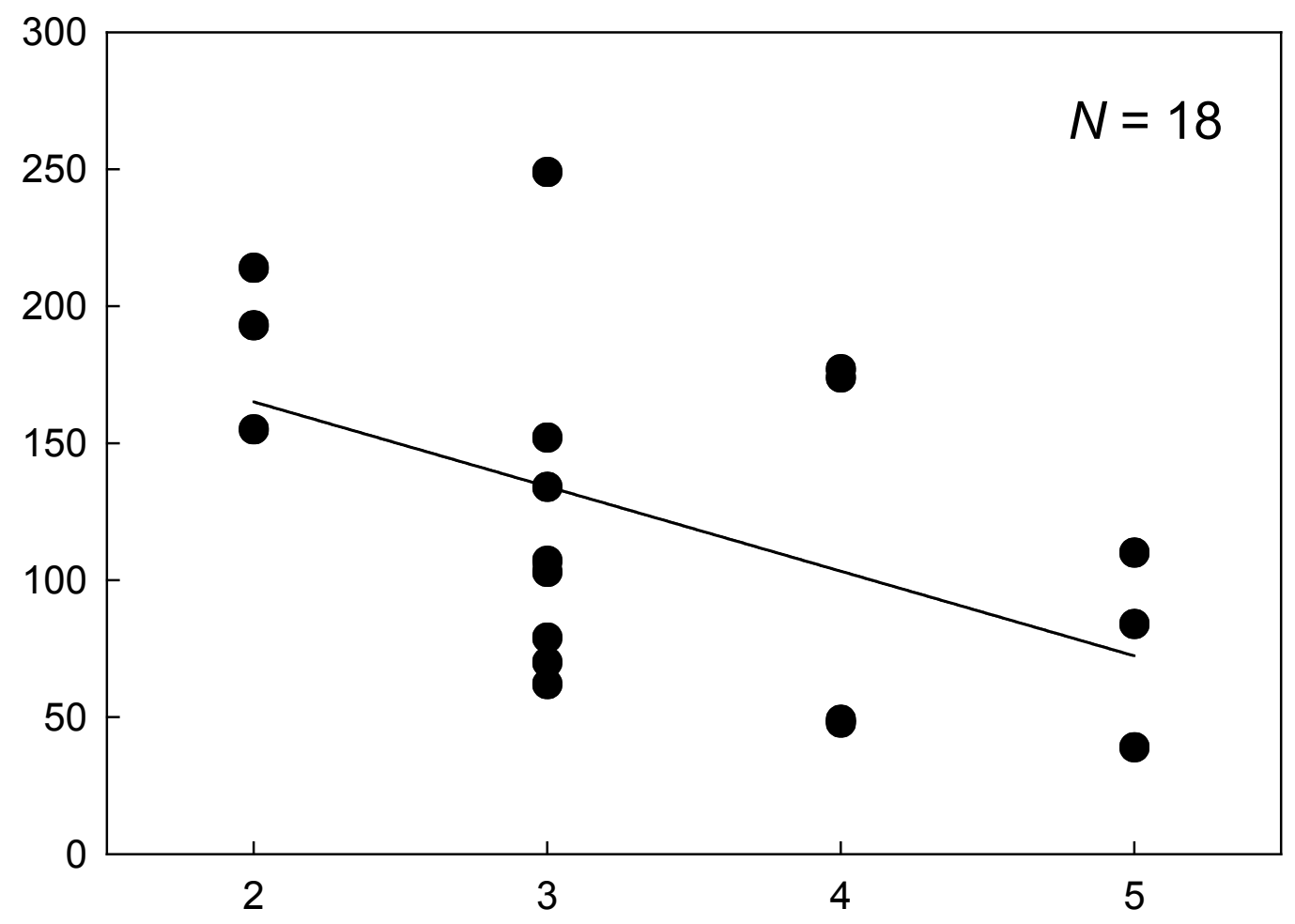

No. of ejaculations during a mating

Figure 3. The relationship between the sperm-removal duration and number of ejaculations during a mating was significantly negative when the last male who had mated with the current partner was a different male rather than the current male. 

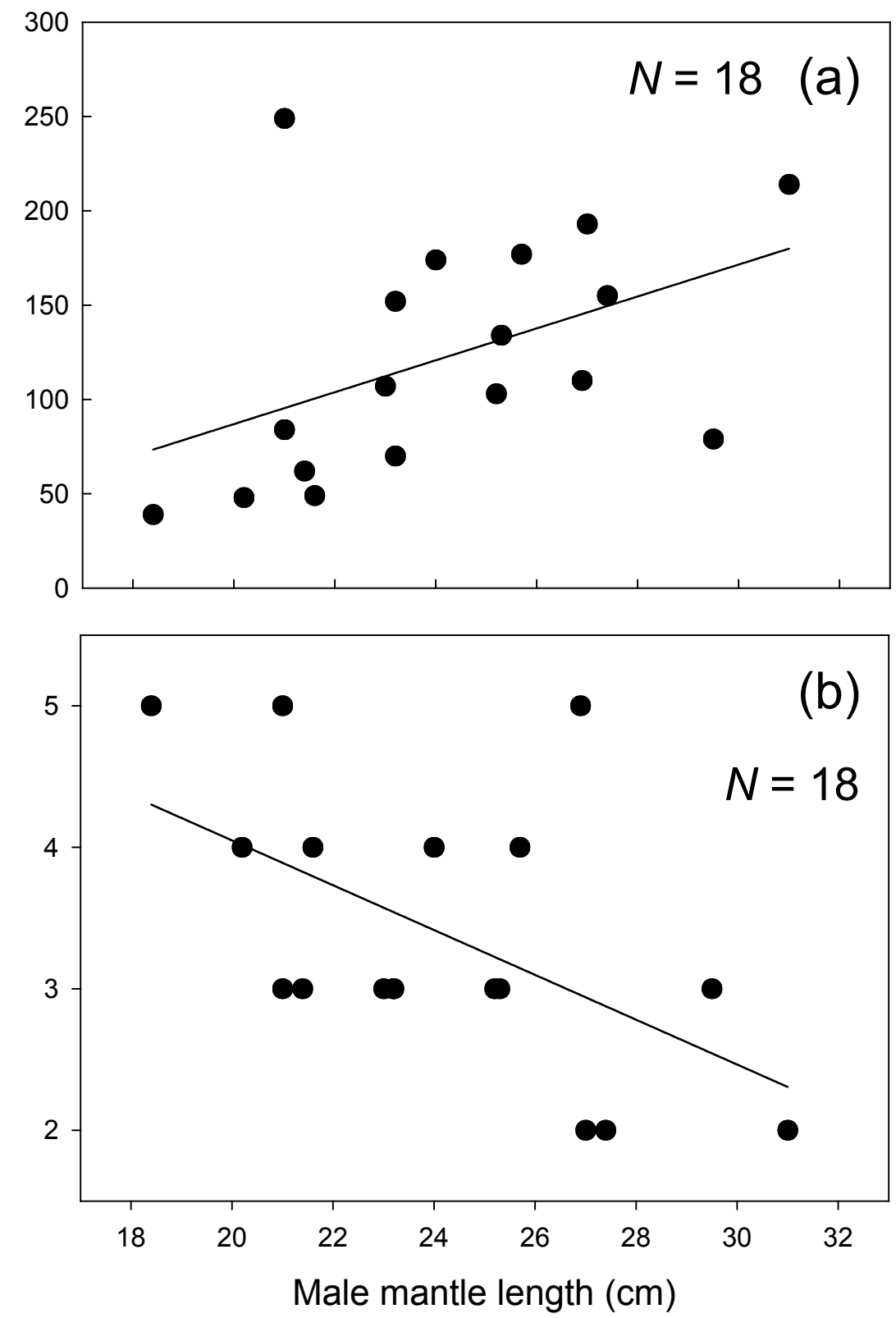

Figure 4. The relationship between male body size and (a) sperm-removal duration and (b) number of ejaculations during a single mating when the last male who had mated with the current partner was a different male. The solid lines represent a significant $(P<0.05)$ correlation. 


\section{Supplementary video legends}

http://www.sciencedirect.com/science/article/pii/S0003347209005624

S.1. In this digital video sequence, we recorded the sperm-removal behaviour of male (left) S. lycidas.

S.2. In this digital video sequence, the male (right) ejaculated spermatophores through his funnel and then transferred them to the female's buccal area with his hectocotylized left fourth arm. During this mating, the ejaculatory behaviour was observed three times. 